ISSN = 1980-993X - doi:10.4136/1980-993X
www.ambi-agua.net
E-mail: ambi-agua@agro.unitau.br
Tel.: (12) 3625-4212

\title{
Avaliação espaço-temporal dos parâmetros de qualidade da água do rio Santa Rita (BA) em função do lançamento de manipueira
}

(http://dx.doi.org/10.4136/ambi-agua.880)

\section{Giovanna Porto dos Santos'; Neylor Alves Calasans Rego ${ }^{2}$; José Wildes Barbosa dos Santos $^{1}$; Franklin Delano Júnior ${ }^{3}$; Milton Ferreira da Silva Júnior ${ }^{2}$}

\author{
${ }^{1}$ Universidade Estadual do Sudoeste da Bahia - UESB, \\ e-mail: giovannaportofm@gmail.com, wildesbarbosa@yahoo.com.br, \\ ${ }^{2}$ Universidade Estadual de Santa Cruz - UESC, \\ e-mail: neylorcalasans@gmail.com, notlimf@gmail.com, \\ ${ }^{3}$ Instituto Federal de Educação, Ciência e Tecnologia da Bahia - IFBA, \\ e-mail: franklin@inside.inf.br
}

\section{RESUMO}

A bacia hidrográfica do rio Santa Rita engloba os povoados de Simão e Campinhos existindo cerca de 150 casas de farinha. O povoado de Campinhos encontra-se entre os maiores beneficiadores de mandioca na região sudoeste da Bahia, gerando muitos empregos diretos e indiretos. A manipueira é um resíduo líquido oriundo da prensagem da mandioca e apresenta alto potencial poluente decorrente da quantidade glicose e frutose, apresentando potencial poluidor 25 vezes maior do que o do esgoto doméstico. O trabalho teve como objetivo a avaliação dos possíveis impactos decorrentes do lançamento de manipueira na qualidade da água do rio Santa Rita. Para tanto, foi elaborado o mapa de uso do solo e realizada a caracterização fisiográfica da bacia, além de efetuadas seis campanhas de coleta de amostras de água em quatro pontos ao longo do rio. Os resultados obtidos indicaram que a bacia hidrográfica do rio Santa Rita é alongada, com baixa eficiência de drenagem e com baixa possibilidade de ocorrência de enchentes. Os dados relativos aos parâmetros de qualidade de água indicaram um forte aporte de efluentes orgânicos nos núcleos de Campinhos e Simão, comprometendo os valores de oxigênio dissolvido, condutividade elétrica, salinidade, amônia, nitrito, nitrato e zinco, sugerindo impactos decorrentes do lançamento de manipueira. A concentração de fósforo total, ferro e cobre foram superiores à jusante da Estação de Tratamento de Esgoto. A água apresentou-se salobra nos três pontos de coleta mais afetados pelo lançamento de manipueira.

Palavras-chave: bacia hidrográfica, qualidade da água, efluentes.

\section{Spatial-temporal water quality parameters evaluation of the Santa Rita river (BA) with respect to the release of manipueira}

\begin{abstract}
The watershed of the river Santa Rita includes the towns of Simão and Campinhos, where exists about 150 flour houses. Campinhos is among the largest cassava processing facilities in the region, generating many direct and indirect jobs. Manipueira is a liquid residue originating from the cassava pressing and presents high pollutant potential due to its high amount of glucose and fructose, this potential is 25 times greater than the one from
\end{abstract}


SANTOS, G. P.; REGO, N. A. C.; SANTOS, J. W. B.; DELANO JÚNIOR, F.; SILVA JÚNIOR, M. F. Avaliação espaço-temporal dos parâmetros de qualidade da água do rio Santa Rita (BA) em função do lançamento de manipueira. Ambi-Agua, Taubaté, v. 7, n. 3, p. 261-278, 2012. (http://dx.doi.org/10.4136/ambiagua.880)

domestic sewer. This work had as objective the evaluation of possible impacts of manipueira release in the water quality of Santa Rita river. For this, the land use map was elaborated and the physiographic characterization developed, besides being performed six campaigns for water samples collection in four sampling points along the river. The obtained results indicated that the watershed is elongated, with low drainage efficiency and it is not prone to flooding. Estimated water quality parameters indicated that organic effluents from Campinhos and Simão impact the values of dissolved oxygen, electrical conductivity, salinity, ammonia, nitrite, nitrate and zinc, suggesting that the water quality of the river Santa Rita is affected by manipueira release. The concentrations of total phosphorus, iron and cooper were superior downstream of the Sewer Treatment Station. The river water was saline in the three sampling points most affected by the release of manipueira.

Keywords: watershed, water quality, effluents.

\section{INTRODUÇÃO}

A água desempenha um papel vital e insubstituível em todo equilíbrio ecológico, sendo um recurso natural imprescindível à manutenção da vida na terra. $\mathrm{O}$ aumento demográfico a que se tem assistido vem provocando a crescente deterioração da água, e à medida que as civilizações aumentam, aumenta a necessidade de água e a poluição da mesma, pois, já é reconhecido que as atividades humanas degradam os sistemas aquáticos.

O Brasil se destaca mundialmente na produção de produtos alimentícios oriundos da mandioca, pois, existem milhares de unidades produtoras de farinha de mandioca distribuídas em seu território, sendo que a maior parte se localiza nas regiões Noroeste, Norte e Sul do país. As casas de farinha são a base da economia de muitas regiões do Brasil, mas também são responsáveis por boa parte da poluição produzida nessas áreas. A queima da lenha polui o ar, provocando doenças respiratórias, juntamente com o despejo da manipueira que polui as águas superficiais, causando intoxicação na população humana e dos ambientes aquáticos.

Segundo Barana (2008), no município de Vitória da Conquista (BA), notadamente nos povoados de Campinhos e Simão, a falta de tratamento adequado da manipueira tem restringido a atividade econômica, por impor limites físicos de espaço destinado à industrialização, pois em determinadas épocas do ano, muitos produtores de farinha são obrigados a reduzir suas atividades pela impossibilidade de descarte destes resíduos nas proximidades das casas de farinha.

O descarte da manipueira sem nenhum tipo de tratamento leva a poluição de uma das poucas fontes de água da região, o rio Santa Rita, e torna o local de produção insalubre pela exposição direta dos moradores ao resíduo despejado abundantemente no ambiente circundante.

A poluição ambiental proveniente da manipueira restringe fisicamente os locais de produção pela formação de enormes volumes deste líquido, provocando condições de insalubridade afetando a saúde da população e a economia desta atividade (Barana, 2008).

A manipueira que em tupi-guarani significa "o que brota da mandioca", é um resíduo líquido da prensagem da raiz de mandioca e apresenta grande potencial poluente, decorrente da quantidade de material não esgotado. Existe também o problema da toxidez, devido a presença de glicosídio característico da planta de mandioca (linamarina) potencialmente hidrolisável a ácido cianídrico (Branco, 1986), tóxico dos mais poderosos e que pode afetar células nervosas. Este glicosídio combina-se com a hemoglobina do sangue, sendo inibidor da cadeia respiratória (Cereda et al., 1981). 
SANTOS, G. P.; REGO, N. A. C.; SANTOS, J. W. B.; DELANO JÚNIOR, F.; SILVA JÚNIOR, M. F. Avaliação espaço-temporal dos parâmetros de qualidade da água do rio Santa Rita (BA) em função do lançamento de manipueira. Ambi-Agua, Taubaté, v. 7, n. 3, p. 261-278, 2012. (http://dx.doi.org/10.4136/ambiagua.880)

A importância econômica da cultura da mandioca deriva do interesse em suas raízes, ricas em amido, utilizadas na alimentação humana e animal, e de seu uso na fabricação de produtos alimentícios e de uso industrial. São exemplos as farinhas de variados tipos, fécula ou polvilho doce, polvilho azedo, amidos modificados, mandioca puba, tapioca, beiju, além das raízes minimamente processadas, congeladas, desidratadas, pré-cozidas, fritas tipo chips e dos croquetes. A mandioca pode ainda ser usada com ingrediente ou aditivo na fabricação de embutidos, chocolates, balas, bolachas, pães e sopas.

Na fabricação da farinha, devido à forma como as raízes são processadas, a concentração da manipueira em matéria orgânica e linamarina é muito elevada, correspondendo à fração aquosa da raiz. O potencial tóxico e poluente é agravado, principalmente, por ser a linamarina muito solúvel em água. Existem relatos de morte de animais que beberam da água onde ocorreram descargas da manipueira, sendo a morte de peixes fato comum. A manipueira apresenta gosto adocicado pela glicose que contém, sendo muito procurada pelos animais (Fioretto, 1987).

A manipueira "in natura", oriunda diretamente da prensagem da raiz de mandioca tem um potencial poluidor de 25 vezes a do esgoto doméstico. A manipueira de fecularia é mais diluída, conserva, porém, um potencial poluidor de aproximadamente 12,5 vezes a do esgoto doméstico (Barana, 2008). Uma tonelada de mandioca produz cerca de $300 \mathrm{~L}$ de manipueira que, quando armazenada, forma verdadeiros lagos. Dessa forma uma fecularia que utilize uma tonelada de raízes de mandioca por dia equivale à poluição ocasionada por 200 a 300 habitantes.dia-1 (Hess, 1962).

Santos (2001) coletou amostra de água do rio Santa Rita à jusante do bairro de Campinhos para análise na EMBASA (Empresa Baiana de Águas e Saneamento S.A) e concluiu que a DQO apresentou valor muito elevado, aproximadamente 30 vezes superior a DQO do esgoto doméstico indicando um consumo bastante elevado de oxigênio devido não só da atividade poluidora do despejo de manipueira, mas provavelmente a outros agentes contaminantes, sendo resultado da atividade de organismos de respiração aeróbica que metabolizam o substrato orgânico acumulando uma fração de glicose que demanda oxigênio do meio para oxidação.

Para Barana (2008), o potencial poluente da manipueira deve-se a carga orgânica que pode chegar a 100 g DQO.L-1. A maior parte da matéria orgânica da manipueira é devida à presença de açúcares solúveis. Este autor determinou os teores dos açúcares glicose e frutose em 10 lotes de manipueira da Farinheira Plaza em Santa Maria da Serra, SP. Em seus resultados a manipueira chegou a apresentar $14,7 \mathrm{~g}$ de glicose.L-1 que correspondeu a $29 \%$ da matéria orgânica presente e $22 \mathrm{~g}$ de frutose.L-1 equivalente a $42 \%$ da matéria orgânica. Por serem açúcares solúveis de fácil fermentação, degradam-se rapidamente a ácidos orgânicos. Esta característica inviabiliza o tratamento deste resíduo por processos físicos.

Segundo Helbig et al. (2008) a toxicidade dos glicosídeos presentes na mandioca foi, primeiramente, relatada no século XVII, no entanto apenas no século XIX houve o primeiro relato de uma intoxicação causada por glicosídeos cianogênicos. Desde esta época são descritos na literatura vários casos de intoxicação e morte devido à ingestão de mandioca e seus derivados.

Ramirez (2010) pesquisando na literatura os efeitos tóxicos do ácido cianídrico sobre humanos e animais, afirmou que mesmo em baixas doses são compostos letais em um tempo mínimo de exposição sendo o sistema nervoso o principal órgão alvo. Após a ingestão, inalação ou contacto os efeitos neurotóxicos são graves e fatais em humanos e animais. A exposição ocupacional produz tireoide, dores de cabeça, tontura, náusea, vômito, dermatites e a alta exposição, e num tempo curto pode levar a insuficiência respiratória e morte. Com 
SANTOS, G. P.; REGO, N. A. C.; SANTOS, J. W. B.; DELANO JÚNIOR, F.; SILVA JÚNIOR, M. F. Avaliação espaço-temporal dos parâmetros de qualidade da água do rio Santa Rita (BA) em função do lançamento de manipueira. Ambi-Agua, Taubaté, v. 7, n. 3, p. 261-278, 2012. (http://dx.doi.org/10.4136/ambiagua.880)

relação à carcinogenicidade, o cianeto é considerado no grupo D (não classificável como carcinogéneo humano).

Segundo Sant'Ana e Domene (2008) já se observou associação entre dietas ricas em mandioca pouco processada e a ocorrência de alterações neurológicas causadas pela presença de glicosídeos cianogênicos (GC) de ocorrência natural.

Neste contexto, o trabalho presente objetiva avaliar os possíveis impactos da manipueira em parâmetros de qualidade da água do rio Santa Rita.

\section{METODOLOGIA}

A bacia hidrográfica do rio Santa Rita pertencente à bacia do Rio Pardo segundo a Superintendência de Recursos Hídricos (Bahia, 2004), engloba os povoados de Simão e Campinhos (Figura 1). O bairro de Campinhos está entre os maiores beneficiadores de mandioca na região, gerando empregos diretos, além dos indiretos em função da lavoura e comercialização dos produtos oriundos da mandioca. A comunidade fica distanciada do centro da cidade de Vitória da Conquista por aproximadamente $9 \mathrm{~km}$.

Segundo Rocha e Barros (2010) a precipitação média anual varia de 800 a $1.500 \mathrm{~mm}$ e a temperatura média anual varia de $21,5^{\circ}$ a $24^{\circ} \mathrm{C}$ A população dos dois povoados é de aproximadamente 6000 habitantes existindo cerca de 150 casas de farinha na região (Rocha e Barros, 2010).

O clima da região varia de semiárido a úmido de acordo com a tipologia climática de Thornthwaite. A vegetação característica é bastante variada, ocorrendo desde floresta perenifólia (mata atlântica), floresta caducifólia e sub-caducifólia, caatinga e cerrado. Com o avanço dos processos de ocupação, observa-se uma grande predominância de áreas ocupadas com pastagens, fruticultura e culturas de subsistência, como milho, feijão e mandioca.

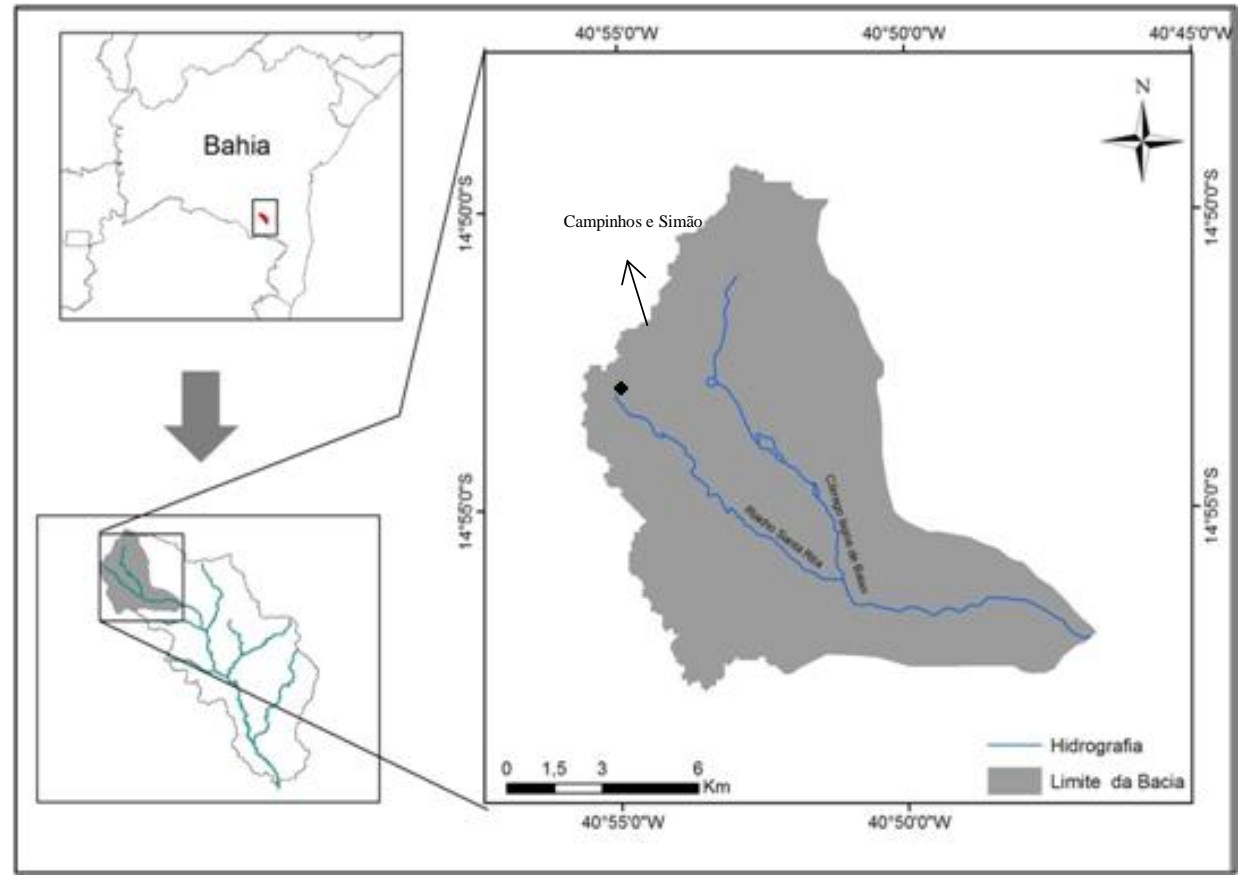

Figura 1. Bacia hidrográfica do rio Santa Rita.

O delineamento da bacia hidrográfica do rio Santa Rita e o mapa de uso do solo foram feitos utilizando-se o Sistema de Informações Geográficas (SIG) ArcView GIS versão 9.2. 
SANTOS, G. P.; REGO, N. A. C.; SANTOS, J. W. B.; DELANO JÚNIOR, F.; SILVA JÚNIOR, M. F. Avaliação espaço-temporal dos parâmetros de qualidade da água do rio Santa Rita (BA) em função do lançamento de manipueira. Ambi-Agua, Taubaté, v. 7, n. 3, p. 261-278, 2012. (http://dx.doi.org/10.4136/ambiagua.880)

A caracterização fisiográfica da bacia hidrográfica foi realizada a partir da determinação do coeficiente de compacidade (Kc), fator de forma (Kf) e densidade de drenagem (Dd), baseado em Bahia (2000).

Os pontos amostrais para as coletas de água foram escolhidos de forma a cobrir longitudinalmente o rio Santa Rita (Figura 2) sendo assim dispostos: ponto P1 localizado na nascente do rio Santa Rita e tem como comunidades ribeirinhas os núcleos comunitários de Campinhos e Simão; P2 à montante da Estação de Tratamento de Esgoto (ETE) da Embasa, logo após o Condomínio Caminho do Parque, localizado no bairro Recreio; P3 em uma área de pastagem muito próximo a rodovia e sem a presença de mata ciliar e o P4, próximo a cidade de Vitória da Conquista e do encontro com o rio Verruga.

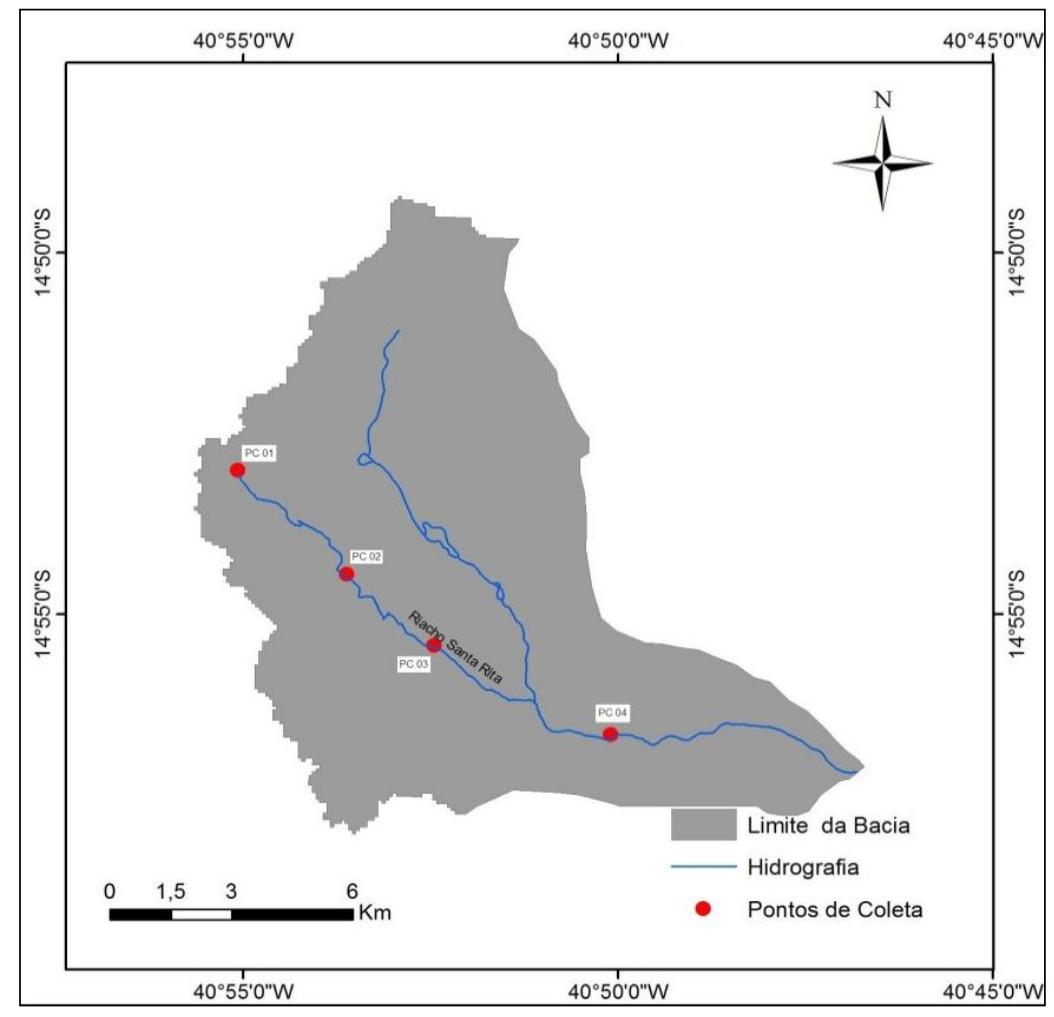

Figura 2. Localização dos pontos de coleta.

As coletas das amostras de água foram feitas utilizando-se recipientes plásticos com volume de 2 L, em 6 datas identificadas como C1 (13/07/2011), C2 (.08/08/2011), C3 (29/09/2011), C4 (24/10/2011), C5 (29/11/2011) e C6 (24/01/2012).

Foram utilizadas caixas de isopor com gelo para acondicionamento das amostras até que fossem conduzidas ao Laboratório de Análise de Água da UESC (Universidade Estadual de Santa Cruz) onde foram refrigeradas a $4^{\circ} \mathrm{C}$ e realizadas as análises num prazo não superior a 24 horas

No Laboratório de Análise de Água da UESC foram realizadas as análises das concentrações de fósforo, amônia, nitrato e nitrito utilizando-se o espectrômetro de ultravioleta. A dosagem das concentrações de ferro, zinco, cobre, manganês e sulfato foram realizadas no Laboratório de Química Analítica da UESC utilizando-se o espectrofotômetro de absorção atômica. Todas as análises foram realizadas segundo a metodologia estabelecida pelo Standard Methods for the Examination for Waterand Wastewater - 20th ed. (APHA et al., 1995). 
SANTOS, G. P.; REGO, N. A. C.; SANTOS, J. W. B.; DELANO JÚNIOR, F.; SILVA JÚNIOR, M. F. Avaliação espaço-temporal dos parâmetros de qualidade da água do rio Santa Rita (BA) em função do lançamento de manipueira. Ambi-Agua, Taubaté, v. 7, n. 3, p. 261-278, 2012. (http://dx.doi.org/10.4136/ambiagua.880)

Em cada um dos pontos selecionados foram realizadas as avaliações da salinidade, condutividade elétrica, oxigênio dissolvido e sólidos totais dissolvidos utilizando-se o equipamento multi-parâmetro HORIBA.

\section{RESULTADOS E DISCUSSÃO}

Os valores referentes às características físicas da bacia hidrográfica do rio Santa Rita, e os índices fisiográficos obtidos estão apresentados na Tabela 1.

Tabela 1. Características físicas da bacia hidrográfica do rio Santa Rita.

\begin{tabular}{l|c}
\hline \multicolumn{2}{c}{ Características físicas } \\
\hline Área de drenagem (A) & $126,84 \mathrm{~km}^{2}$ \\
Perímetro total (P) & $66,65 \mathrm{~km}$ \\
Comprimento do rio principal (L) & $19,63 \mathrm{~km}$ \\
Comprimento total dos cursos de água (Lt) & $34,3 \mathrm{~km}$ \\
Desnível máximo & $900,00 \mathrm{~m}$ \\
Coeficiente de Compacidade (Kc) & 1,65 \\
Fator de Forma (Kf) & 0,33 \\
Densidade de Drenagem (Dd) & $0,27 \mathrm{~km} \cdot \mathrm{km}^{-2}$ \\
\hline
\end{tabular}

A bacia hidrográfica do rio Santa Rita possui uma área de $126,84 \mathrm{~km}^{2}$. O comprimento do canal principal é de $19,63 \mathrm{~km}$ com uma rede de drenagem total de $34,3 \mathrm{~km}$. A densidade de drenagem é de $0,27 \mathrm{~km} / \mathrm{km}^{2}$, indicando uma baixa capacidade de drenagem, apresentando relevo pouco declivoso com rampas longas.

Christofoletti (1969) destaca que valores menores que $7,5 \mathrm{~km} / \mathrm{km}^{2}$ indicam baixa densidade de drenagem. Valores entre 7,5 e $10,0 \mathrm{~km} / \mathrm{km}^{2}$ indicam média densidade. Já valores acima de $10,0 \mathrm{~km} / \mathrm{km}^{2}$, indicam alta densidade hidrográfica.

A densidade de drenagem é um fator importante na indicação do grau de desenvolvimento do sistema de drenagem de uma bacia. Sendo assim, este índice, fornece uma indicação da eficiência da drenagem da bacia, sendo expressa pela relação entre o somatório dos comprimentos de todos os canais da rede; sejam eles perenes, intermitentes ou temporários e a área total da bacia (Antoneli e Thomaz, 2007).

Já de acordo com Villela e Mattos (1975), esse mesmo índice (densidade de drenagem), pode variar de $0,5 \mathrm{~km} / \mathrm{km}^{2}$ em bacias com drenagem pobre, a $3,5 \mathrm{~km} / \mathrm{km}^{2}$, ou mais, em bacias bem drenadas, indicando, também, que a bacia em estudo possui baixa capacidade de drenagem.

A bacia em estudo possui forma alongada, aproximando-se do retângulo com $\mathrm{Kc}>1,25 \mathrm{e}$ Kf < 0,5 (Tonello et al., 2006; Périco et al., 2011) apresentando menor possibilidade de enchentes rápidas em condições normais de precipitação.

O mapa de uso do solo é apresentado na Figura 3, no qual se pode observar que a área com ocupação urbana representa aproximadamente $32 \%$ da área total da bacia hidrográfica incluindo os povoados de Campinhos e Simão e parte da cidade de Vitória da Conquista. Observa-se também que o entorno da área com ocupação urbana sendo utilizado basicamente com pastagem e algumas áreas com solo exposto. A região abrangida pelo baixo curso do rio Santa Rita é a que apresenta o maior percentual de áreas ocupadas com florestas e onde está localizado o ponto de coleta 4. A Tabela 2 apresenta informações referentes aos diversos usos. 
SANTOS, G. P.; REGO, N. A. C.; SANTOS, J. W. B.; DELANO JÚNIOR, F.; SILVA JÚNIOR, M. F. Avaliação espaço-temporal dos parâmetros de qualidade da água do rio Santa Rita (BA) em função do lançamento de manipueira. Ambi-Agua, Taubaté, v. 7, n. 3, p. 261-278, 2012. (http://dx.doi.org/10.4136/ambiagua.880)

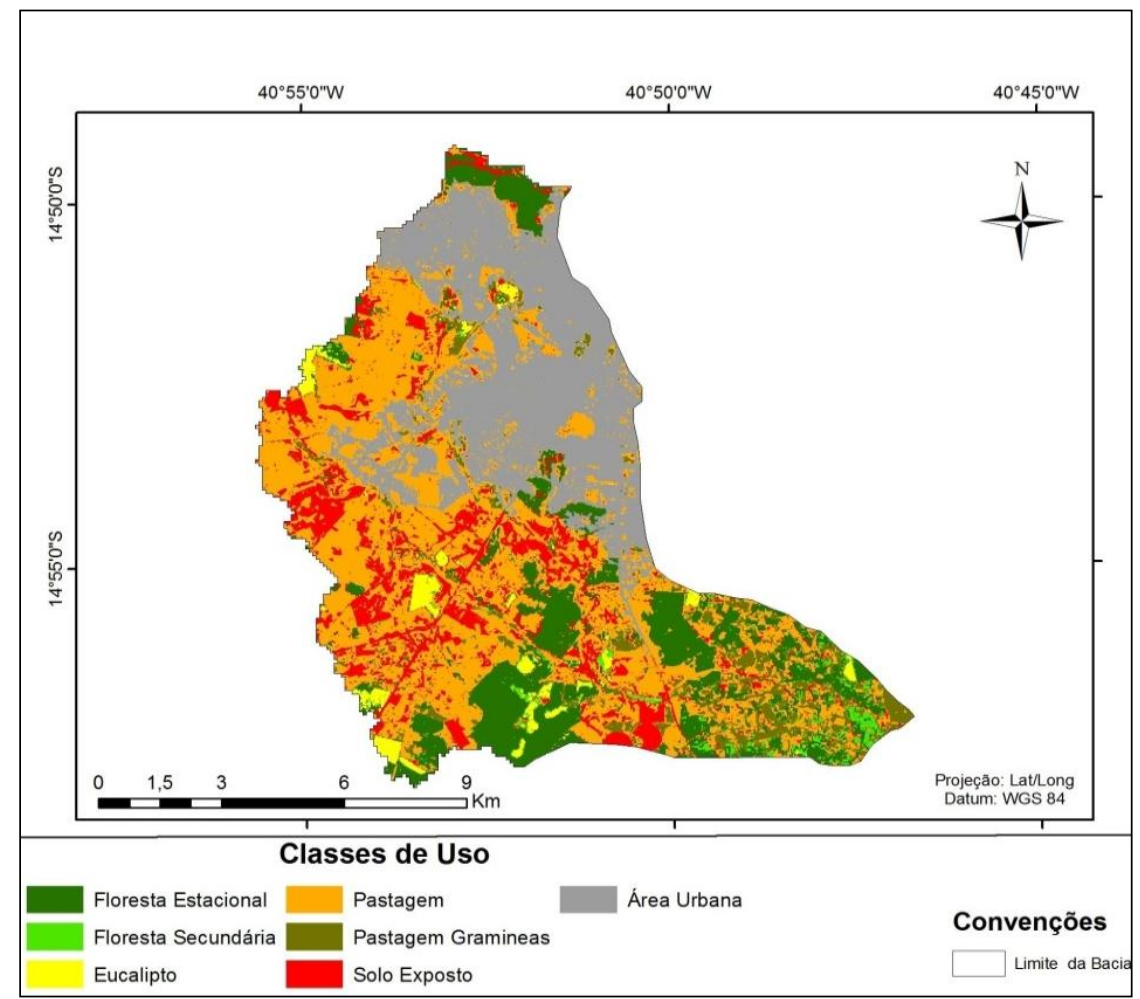

Figura 3. Mapa de uso do solo.

Tabela 2. Classes de uso do solo.

\begin{tabular}{l|cr}
\hline Classes de Uso do Solo & Área $\left(\mathbf{k m}^{\mathbf{2}}\right)$ & Área $\mathbf{( \% )}$ \\
\hline Pastagem & 47,45 & 37,41 \\
Pastagem gramínea & 7,55 & 5,95 \\
Floresta & 19,57 & 15,43 \\
Floresta secundária & 1,99 & 1,57 \\
Solo exposto & 15,29 & 12,05 \\
Eucalipto & 3,00 & 2,37 \\
Área urbana & 31,99 & 25,22 \\
\hline Total & $\mathbf{1 2 6 , 8 4}$ & $\mathbf{1 0 0 , 0 0}$ \\
\hline
\end{tabular}

A média, erro padrão e desvio padrão para os valores de oxigênio dissolvido (OD) obtidos nos pontos de coleta estão apresentados na Figura 4, na qual se pode observar que somente o ponto $\mathrm{P} 4$ apresentou valores médios superiores a $4 \mathrm{mg} . \mathrm{L}^{-1}$ e portanto podendo ser enquadrado como classe III pela Resolução CONAMA 357/2005 (Brasil, 2005).

Para os pontos de coleta P1, P2 os valores médios de OD observados indicam uma forte poluição, tais resultados estão associados ao potencial poluente da manipueira em virtude de sua carga orgânica, cuja principal origem é a atividade econômica desenvolvida nesse trecho da bacia hidrográfica, que é o beneficiamento da mandioca. Muito embora o ponto de coleta P3 tenha apresentado valores inferiores a $4 \mathrm{mg} . \mathrm{L}^{-1}$ pode-se observar que há um sensível aumento nos valores de $\mathrm{OD}$, sendo que, para o ponto de coleta $\mathrm{P} 4 \mathrm{o}$ valores observados foram superiores a $4 \mathrm{mg} . \mathrm{L}^{-1}$, sugerindo desta forma que mecanismos de aeração contribuam para a elevação dos níveis de oxigênio dissolvido. 
SANTOS, G. P.; REGO, N. A. C.; SANTOS, J. W. B.; DELANO JÚNIOR, F.; SILVA JÚNIOR, M. F. Avaliação espaço-temporal dos parâmetros de qualidade da água do rio Santa Rita (BA) em função do lançamento de manipueira. Ambi-Agua, Taubaté, v. 7, n. 3, p. 261-278, 2012. (http://dx.doi.org/10.4136/ambiagua.880)

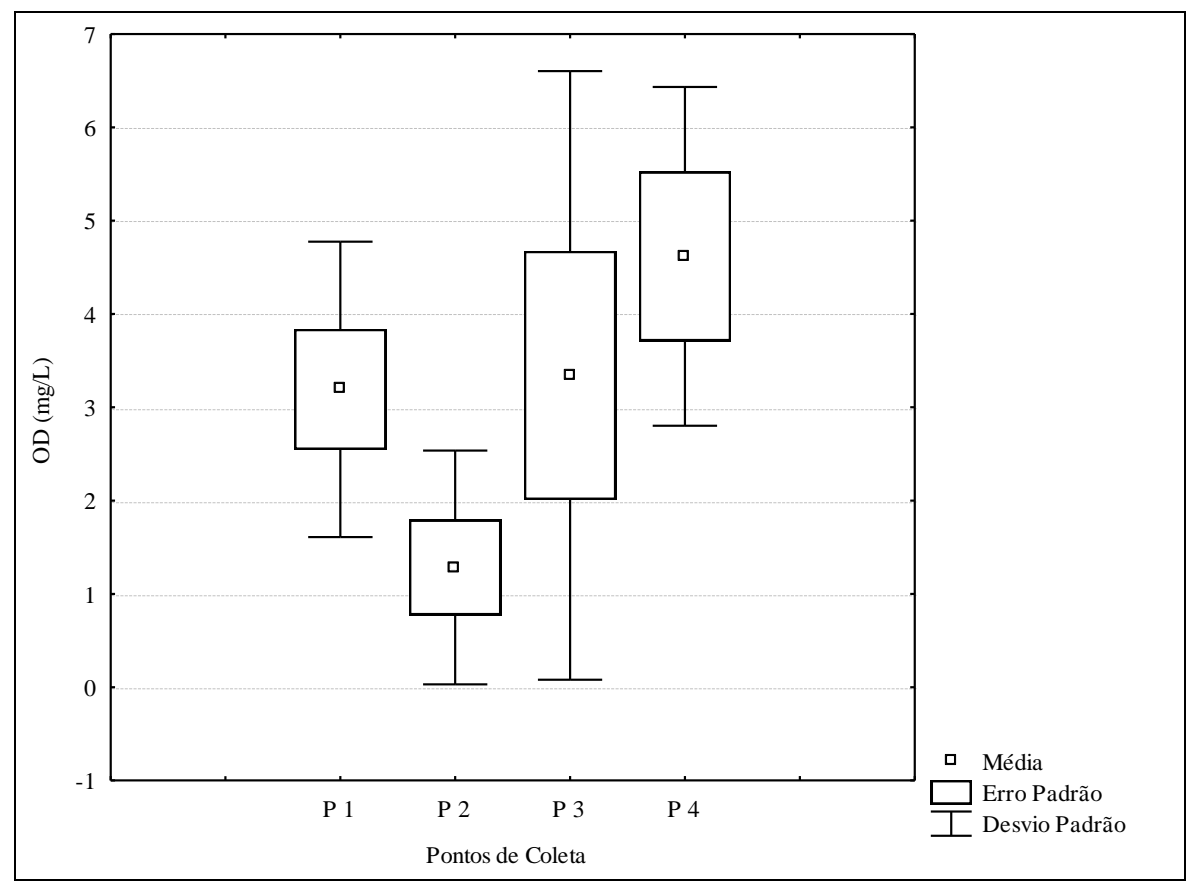

Figura 4. Média, erro padrão e desvio padrão de OD, para os diferentes pontos de coleta.

Os valores médios da condutividade elétrica (CE) obtidos nas coletas estão apresentados na Figura 5. Conforme pode ser observado, os valores médios obtidos para os pontos P1, P2 e P3 indicam um ambiente fortemente impactado (CETESB, 2007) pelo lançamento de efluentes.

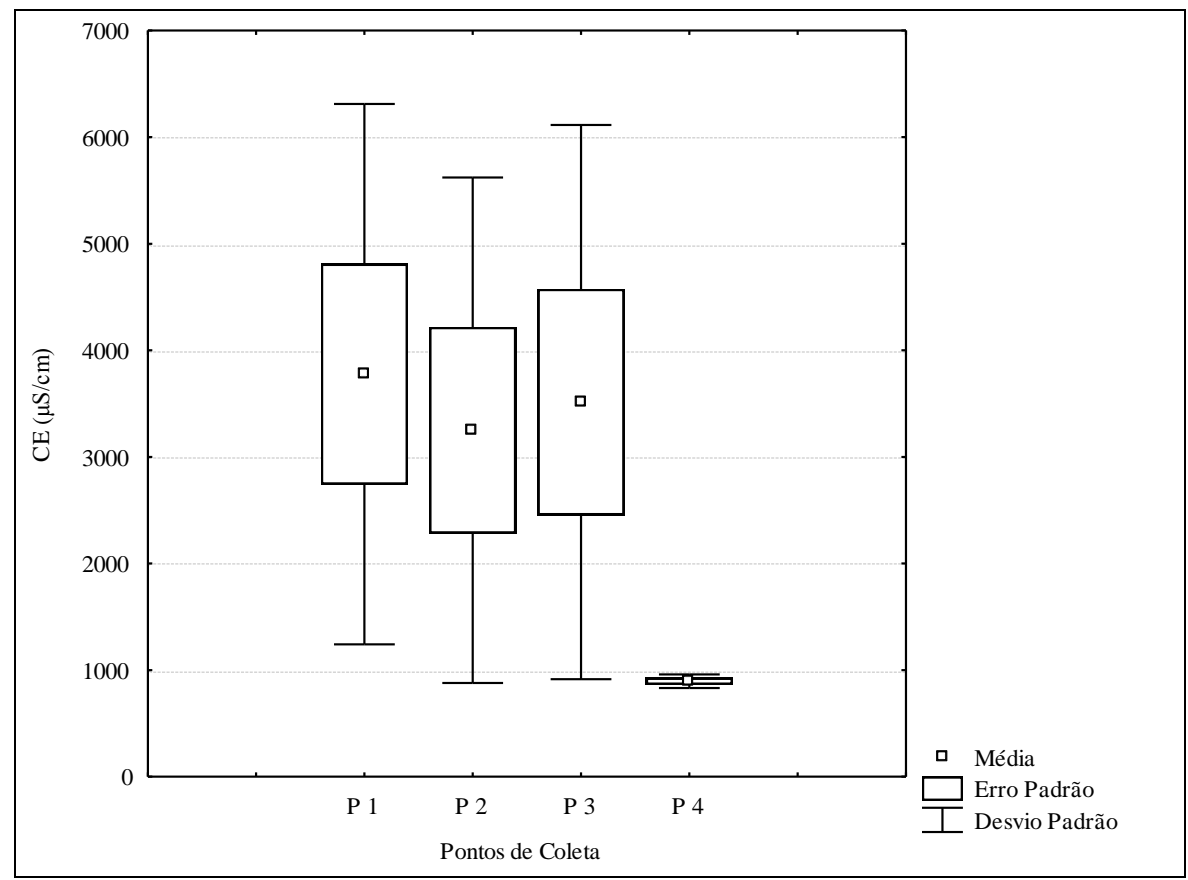

Figura 5. Média, erro padrão e desvio padrão de CE, para os diferentes pontos de coleta. 
SANTOS, G. P.; REGO, N. A. C.; SANTOS, J. W. B.; DELANO JÚNIOR, F.; SILVA JÚNIOR, M. F. Avaliação espaço-temporal dos parâmetros de qualidade da água do rio Santa Rita (BA) em função do lançamento de manipueira. Ambi-Agua, Taubaté, v. 7, n. 3, p. 261-278, 2012. (http://dx.doi.org/10.4136/ambiagua.880)

Vale ressaltar que a alta amplitude nos valores de condutividade elétrica, possivelmente estejam associados aos aspectos sazonais da atividade produtiva local, ou seja, períodos onde ocorrem uma maior intensidade no beneficiamento da mandioca potencializando uma maior carga de poluente para as águas do rio, elevando desta forma os teores de sais e matéria orgânica. Apesar de também bastante elevada, a média obtida para o ponto P4 mostra melhoria nas condições realtivas a quantidade de sais existentes na coluna d'água.

A Figura 6 mostra os valores da média, erro padrão e desvio padrão da salinidade nos 4 pontos de coleta, podendo-se observar a maior média no ponto de P1 e a menor no ponto P4. Em relação aos valores estabelecidos pela Resolução CONAMA 357/2005, a água coletada no ponto de P4 é classificada como doce e para os demais locais classificada como salobra.

Nos pontos P1, P2 e P3 a elevada salinidade pode restringir a utilização da água para abastecimento doméstico devido aos possíveis agravos à saúde da população, irrigação pela possibilidade de salinização dos solos e uso industrial pelas características de corrosão e incrustação (Rego et al., 2009)

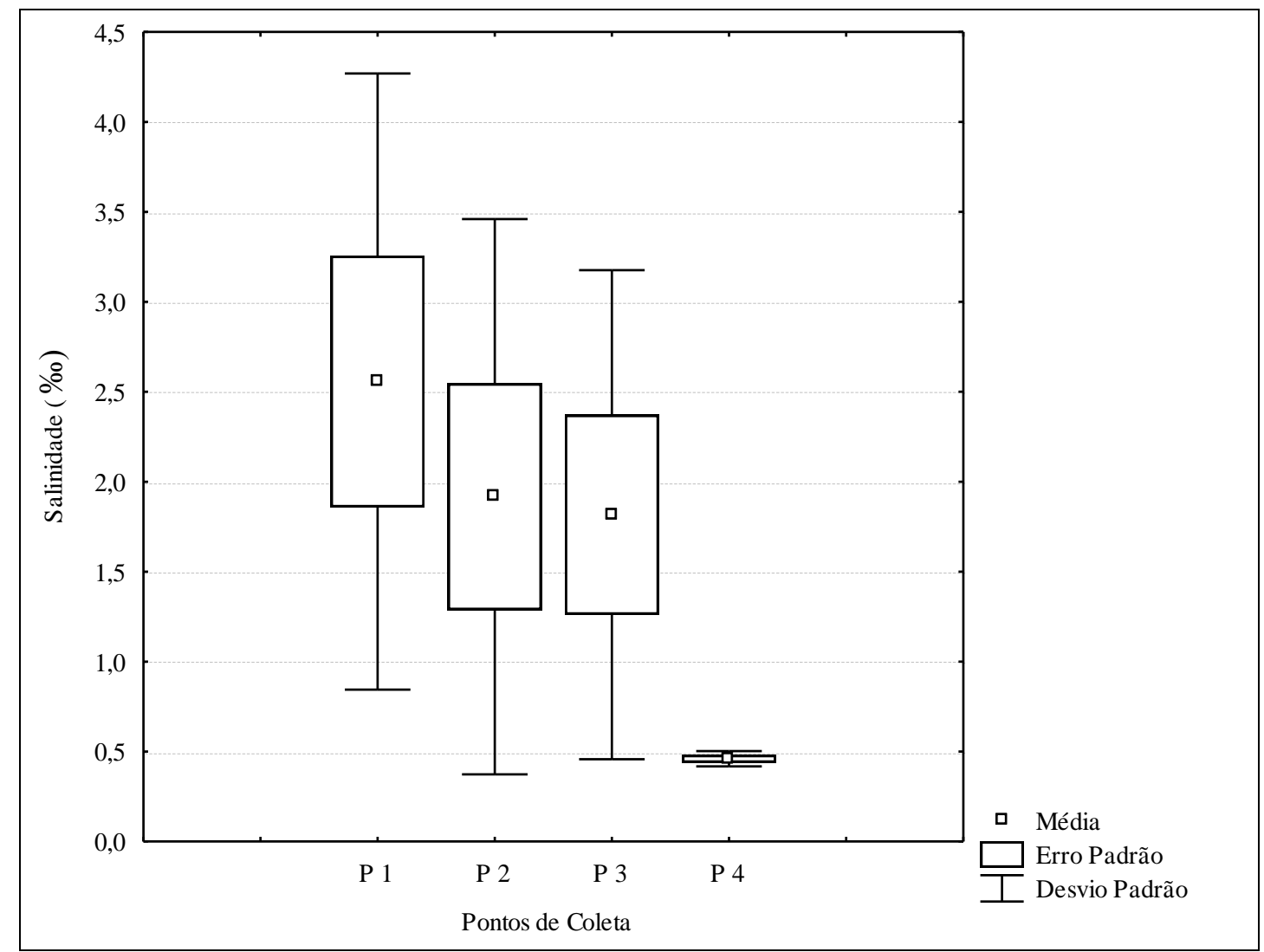

Figura 6. Média, erro padrão e desvio padrão da salinidade, para os diferentes pontos de coleta.

Em relação à concentração de sólidos totais dissolvidos (STD) e os 4 pontos amostrais, somente o ponto P4 apresentou valores médios inferiores a $500 \mathrm{mg} . \mathrm{L}^{-1}\left(469 \mathrm{mg} . \mathrm{L}^{-1}\right)$ sendo que a maior média foi a do ponto P1 e as concentrações decrescendo a jusante deste ponto (Figura 7), indicando o lançamento de efluentes neste ponto com alta carga de constituintes minerais.

De acordo com a Resolução CONAMA 357/2005, o limite máximo para o STD é de $500 \mathrm{mg} . \mathrm{L}^{-1}$ para as classes I, II e III 
SANTOS, G. P.; REGO, N. A. C.; SANTOS, J. W. B.; DELANO JÚNIOR, F.; SILVA JÚNIOR, M. F. Avaliação espaço-temporal dos parâmetros de qualidade da água do rio Santa Rita (BA) em função do lançamento de manipueira. Ambi-Agua, Taubaté, v. 7, n. 3, p. 261-278, 2012. (http://dx.doi.org/10.4136/ambiagua.880)

Os valores médios de STD e sua concentração ao longo do rio Santa Rita obtidos neste trabalho são diferentes dos apresentados por Lage (2011) que estudando o rio Piabanha (BA) encontrou valores que variaram de 78,01 a $302,29 \mathrm{mg} . \mathrm{L}^{-1}$ observando crescentes concentrações de STD ao longo do rio. Fernandes (2011), avaliando a qualidade da água no trecho urbano do rio de Contas também encontrou valores médios muito inferiores aos obtidos para o rio Santa Rita (de 219 a $296 \mathrm{mg} \cdot \mathrm{L}^{-1}$ ).

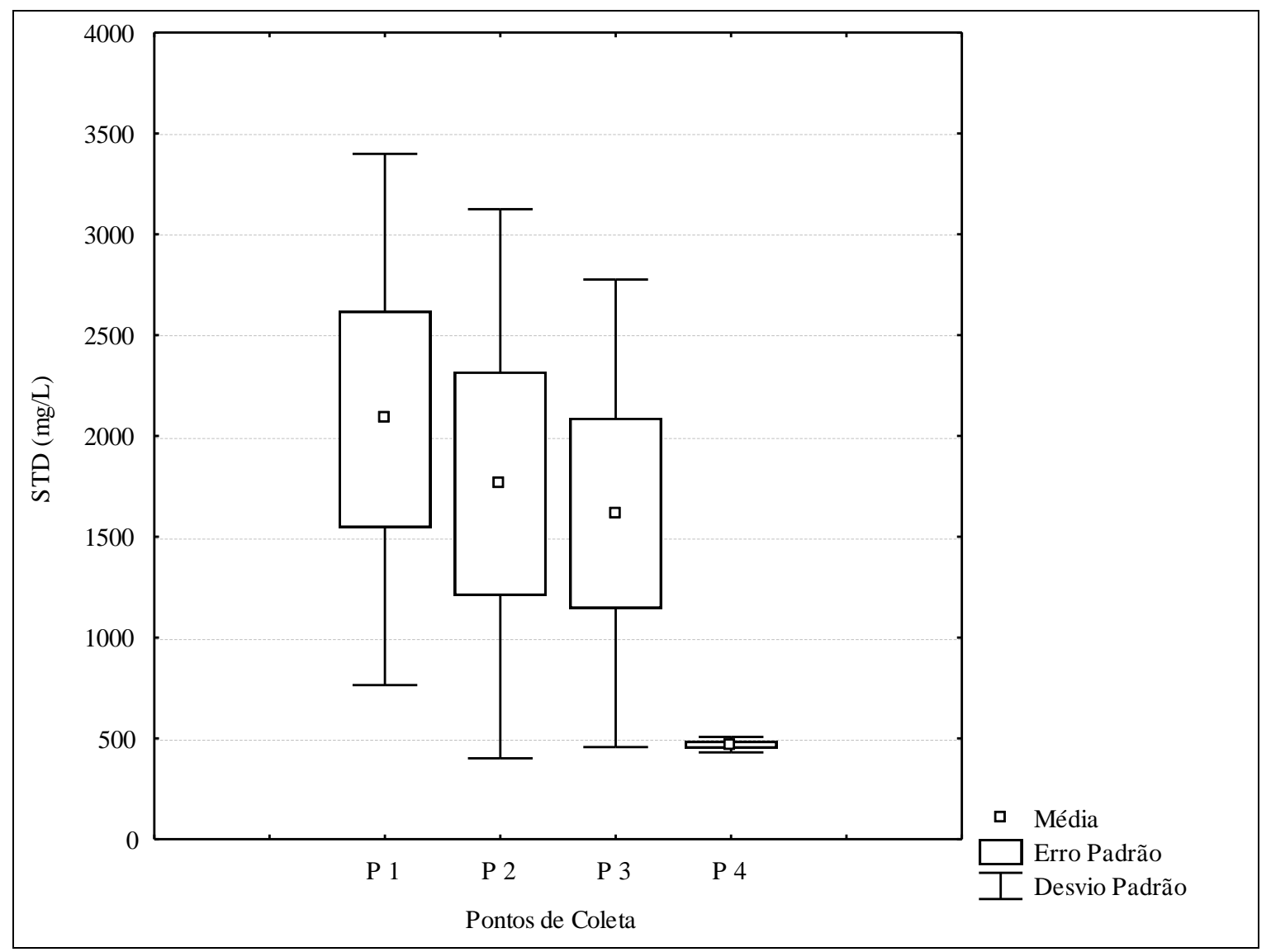

Figura 7. Média, erro padrão e desvio padrão do STD, para os diferentes Pontos de coleta.

A Figura 8 apresenta os valores obtidos para a concentração de fósforo total nos pontos de coleta, podendo-se observar as maiores médias nos pontos P1 e P3. Em face aos resultados encontrados a origem do fósforo nas águas do rio Santa Rita vêm do lançamento de efluentes ricos em matéria orgânica dos núcleos comunitários de Campinhos e Simão onde localiza-se o ponto de coleta P1 e da carga orgânica das atividade agrícolas como fertilizantes e dejetos de origem animal, pois o ponto de coleta P3 está localizado em uma região da atividade agropastoril.

Considerando a Resolução CONAMA 357/2005 e os limites estabelecidos para águas doces, os pontos P1 e P3 classificam-se como de classe IV e os pontos P2 e P4 como de classe I. Quando a salinidade da água é considerada e sendo os pontos P1, P2 e P3 classificados como de água salobra, os limites estabelecidos pela Resolução CONAMA 357/2005 indicam o ponto P1 como de classe II (limite de $0,186 \mathrm{mg} . \mathrm{L}^{-1}$ ), o ponto P2 de classe I (limite de $0,124 \mathrm{mg} . \mathrm{L}^{-1}$ ) e o ponto P3 como de Classe III (concentração média maior que $0,186 \mathrm{mg} . \mathrm{L}^{-1}$ ). 
SANTOS, G. P.; REGO, N. A. C.; SANTOS, J. W. B.; DELANO JÚNIOR, F.; SILVA JÚNIOR, M. F. Avaliação espaço-temporal dos parâmetros de qualidade da água do rio Santa Rita (BA) em função do lançamento de manipueira. Ambi-Agua, Taubaté, v. 7, n. 3, p. 261-278, 2012. (http://dx.doi.org/10.4136/ambiagua.880)

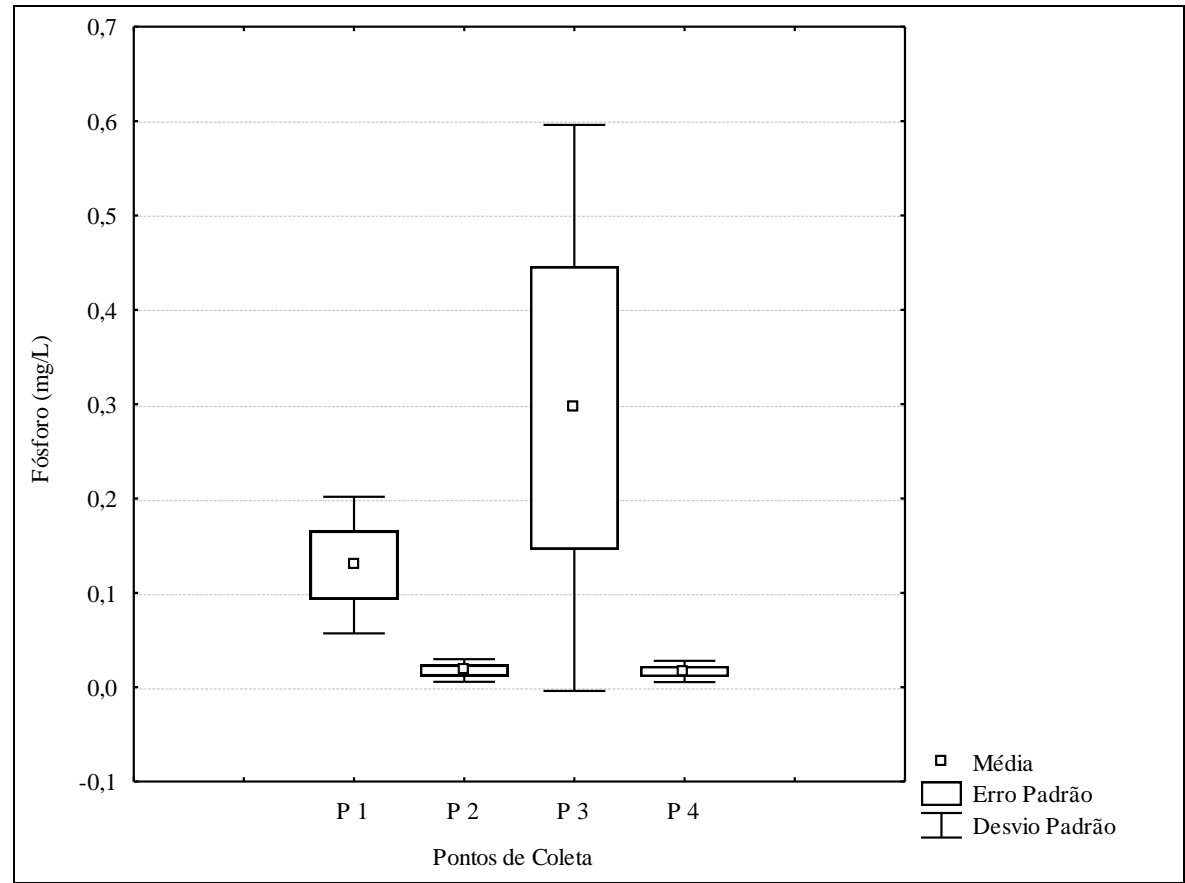

Figura 8. Média, erro padrão e desvio padrão do fósforo, para os diferentes pontos de coleta.

A Figura 9 mostra os valores médios obtidos da concentração de ferro, sendo observada para o rio Santa Rita, a maior média no ponto P3, provavelmente devido aos efeitos dos efluentes da ETE e ao escoamento de fertilizantes da área de agricultura nas proximidades do ponto de coleta (Lima et al., 2001).

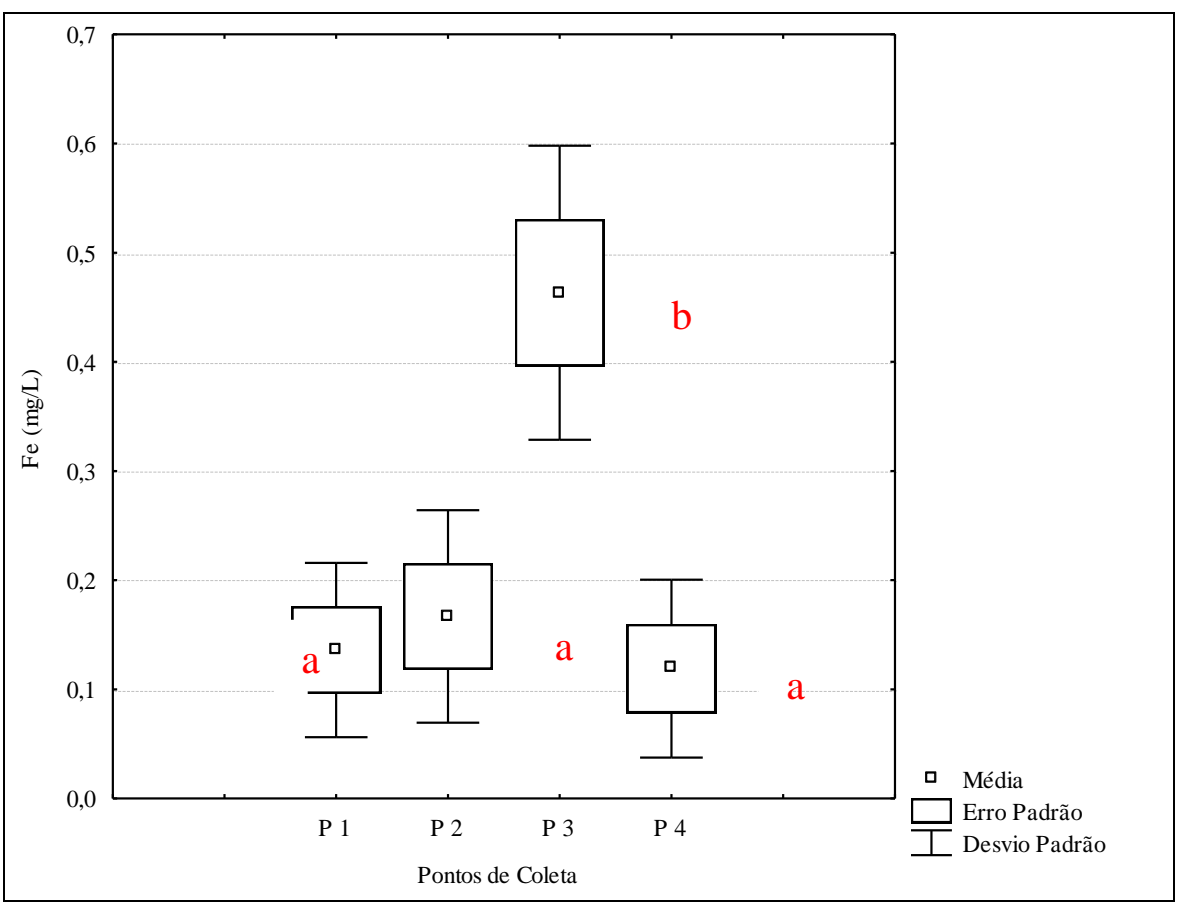

Figura 9. Média, erro padrão e desvio padrão de ferro, para os diferentes pontos de coleta.

Nota: Letras iguais significam a não existências de diferenças estatísticas significativas a $5 \%$ de probabilidade. 
SANTOS, G. P.; REGO, N. A. C.; SANTOS, J. W. B.; DELANO JÚNIOR, F.; SILVA JÚNIOR, M. F. Avaliação espaço-temporal dos parâmetros de qualidade da água do rio Santa Rita (BA) em função do lançamento de manipueira. Ambi-Agua, Taubaté, v. 7, n. 3, p. 261-278, 2012. (http://dx.doi.org/10.4136/ambiagua.880)

Considerando-se os limites da Resolução CONAMA 357/2005, somente o ponto P3 (0,46 mg. $\left.\mathrm{L}^{-1}\right)$ ultrapassa os limites da classe II, enquadrando-se na classe III.

Assim como o observado para o ferro, a Figura 10 mostra que a concentração de cobre também foi maior no ponto P3, possivelmente, esses valores tenham a mesma origem observada nos teores de fósforo, onde as atividades agrícolas estejam contribuindo para esse valor diferenciado em relação aos demais pontos de coleta, pois, escoamento de fungicidas e/ou pesticidas da área de agricultura podem contribuir para elevação de metais nas águas superficiais (Philippi et al., 2004). Como as concentrações médias em todos os pontos foram inferiores a $0,09 \mathrm{mg} . \mathrm{L}^{-1}$, todos os 4 pontos são classificados como classe I, de acordo com a Resolução CONAMA 357/2005.

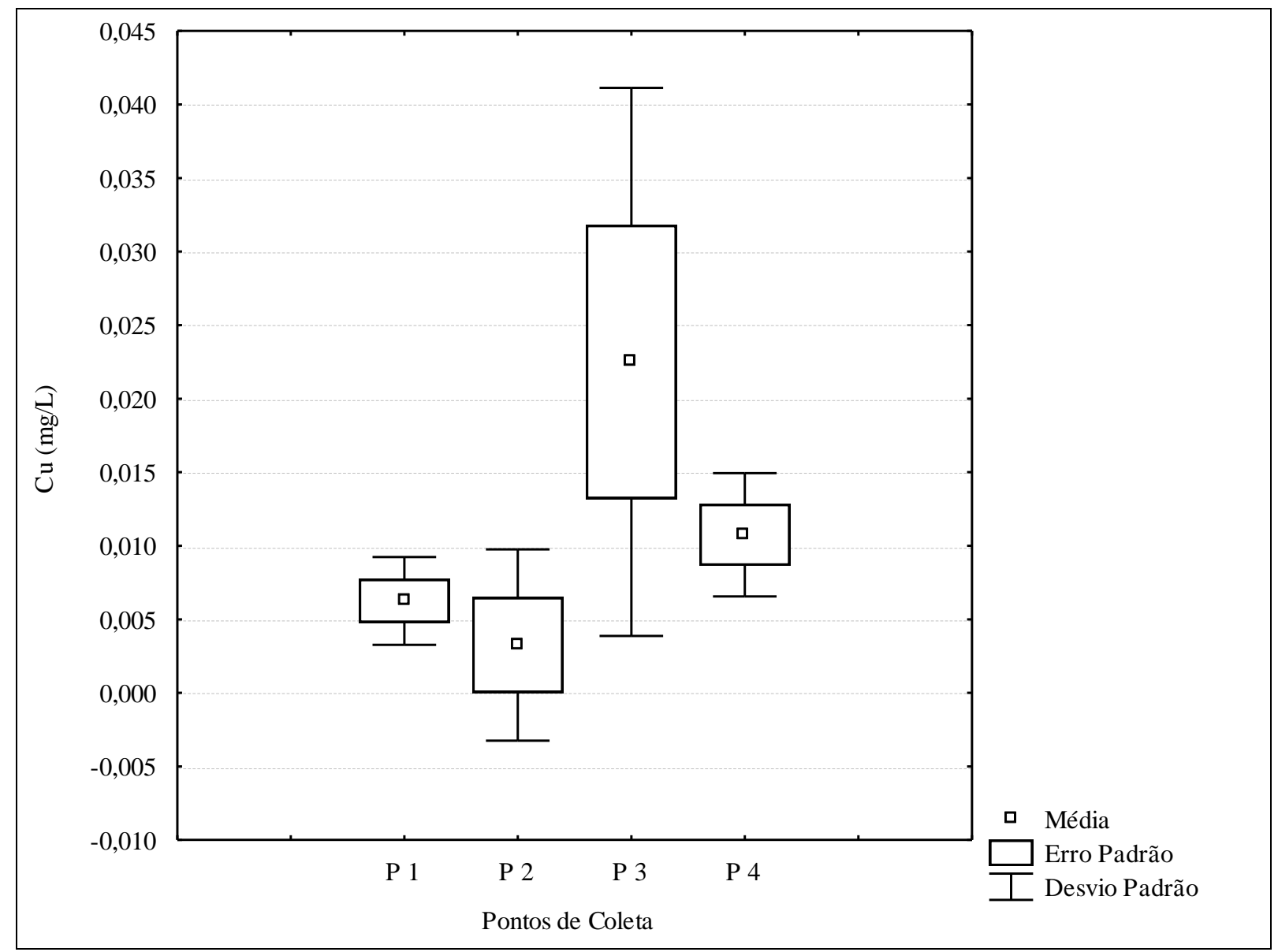

Figura 10. Média, erro padrão e desvio padrão de cobre, para os diferentes pontos de coleta.

A Figura 11 mostra as concentrações médias obtidas para o zinco nos pontos de coleta. Observa-se na referida figura as maiores médias no ponto P1 localizado próximo aos núcleos de Campinhos e Simão, provavelmente, devido a queima de madeira, lançamento de efluentes domésticos e incineração de resíduos (Philippi et al., 2004).

De acordo com a Resolução CONAMA 357/2005 todos os pontos de coleta são enquadrados como de classe I (concentração média menor que $0,18 \mathrm{mg} . \mathrm{L}^{-1}$ ). 
SANTOS, G. P.; REGO, N. A. C.; SANTOS, J. W. B.; DELANO JÚNIOR, F.; SILVA JÚNIOR, M. F. Avaliação espaço-temporal dos parâmetros de qualidade da água do rio Santa Rita (BA) em função do lançamento de manipueira. Ambi-Agua, Taubaté, v. 7, n. 3, p. 261-278, 2012. (http://dx.doi.org/10.4136/ambiagua.880)

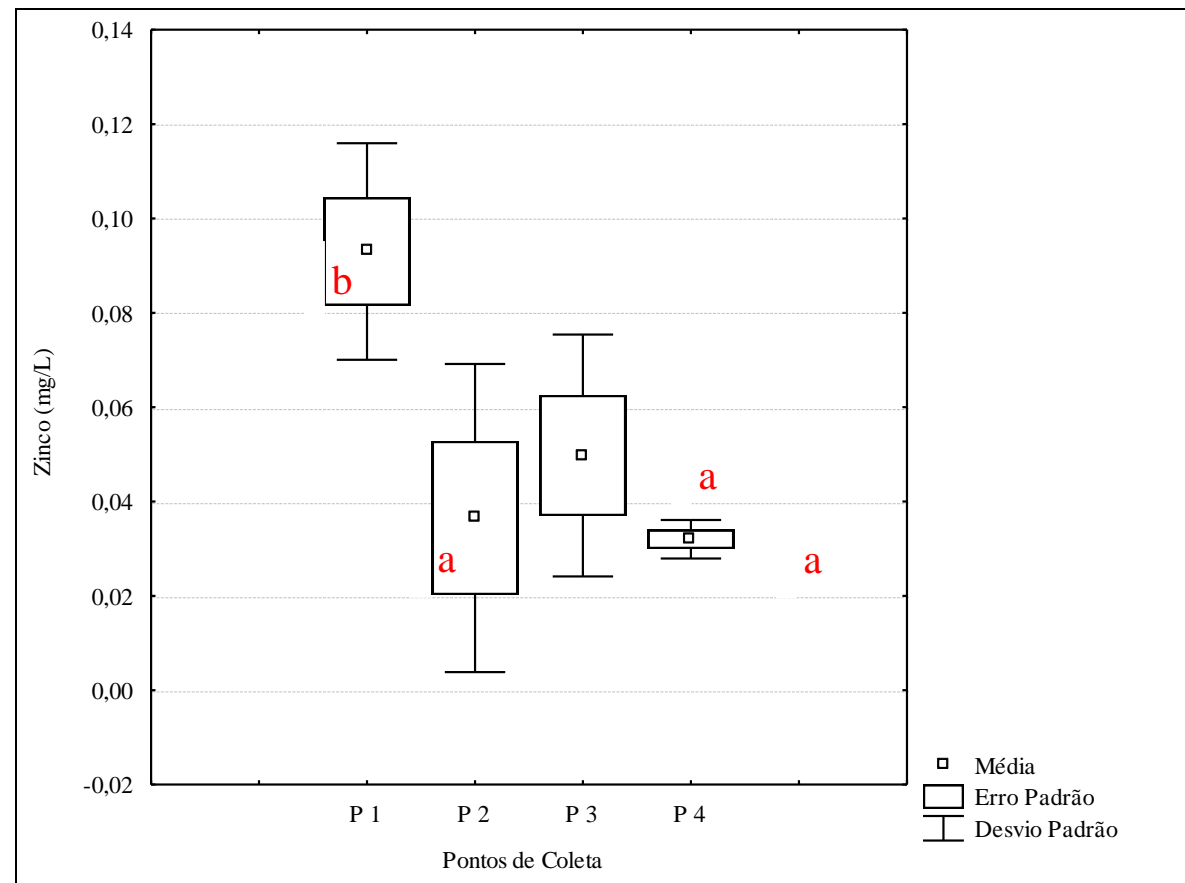

Figura 11. Média, erro padrão e desvio padrão de zinco, para os diferentes pontos de coleta.

A Figura 12 mostra a média, erro padrão e desvio padrão da concentração de amônia nos 4 pontos de coleta, podendo-se observar os maiores valores nos pontos P1 e P2 devido a degradação da matéria orgânica lançada no rio Santa Rita nestas localidades.

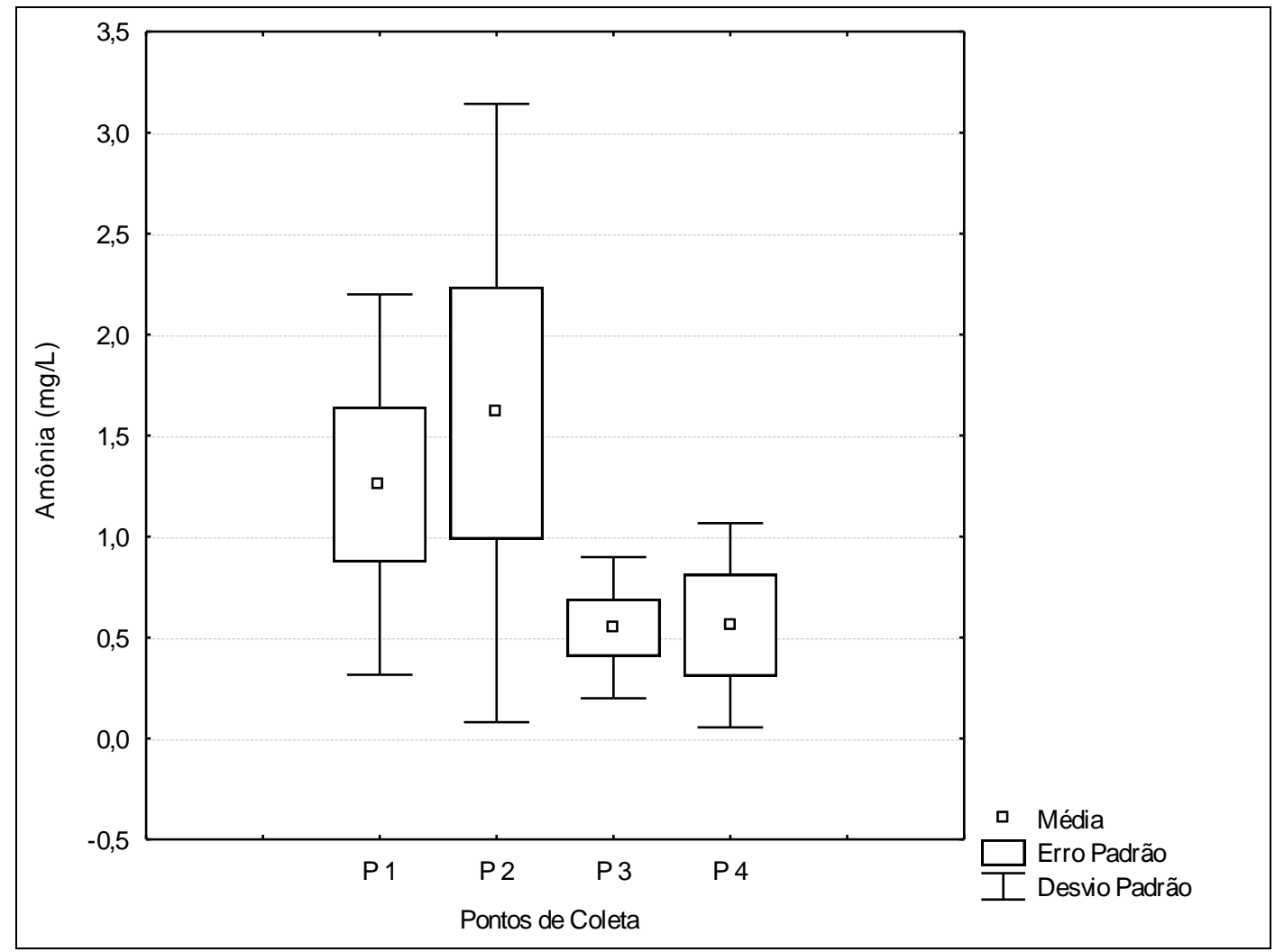

Figura 12. Média, erro padrão e desvio padrão de amônia, para os diferentes pontos de coleta. 
SANTOS, G. P.; REGO, N. A. C.; SANTOS, J. W. B.; DELANO JÚNIOR, F.; SILVA JÚNIOR, M. F. Avaliação espaço-temporal dos parâmetros de qualidade da água do rio Santa Rita (BA) em função do lançamento de manipueira. Ambi-Agua, Taubaté, v. 7, n. 3, p. 261-278, 2012. (http://dx.doi.org/10.4136/ambiagua.880)

O nitrogênio amoniacal é a forma mais reduzida do nitrogênio e é o primeiro composto produzido na degradação da matéria orgânica (A.P.H.A, 1995). Muito embora a amônia orgânica seja toxica, é mais volátil, contudo, os valores médios obervados nos pontos de coleta $\mathrm{P} 1$ e $\mathrm{P} 2$, acima de $1,0 \mathrm{mg} / \mathrm{L}$, indicam um sistema altamente poluído que associado aos níveis de oxigênio e metais pesados potencializam a sua carga tóxica.

A Figura 13 apresenta os valores da média, do erro padrão e desvio padrão das concentrações de nitrito nos 4 pontos de coleta podendo-se observar o maior valor do ponto P1 e o decréscimo nos pontos P2, P3 e P4. Este comportamento deve-se provavelmente ao fato do despejo de matéria orgânica no rio que ocorre nos núcleos de Campinhos e Simão. Concentrações elevadas de nitrito afetam a concentração dos glóbulos vermelhos do sangue reduzindo a capacidade respiratória dos organismos aquáticos podendo provocar a morte dos mesmos por asfixia.

Em relação à Resolução CONAMA 357/2005, a concentração média em todos os pontos foi inferior a $1,0 \mathrm{mg} . \mathrm{L}^{-1}$ e portanto enquadrados como classe I.

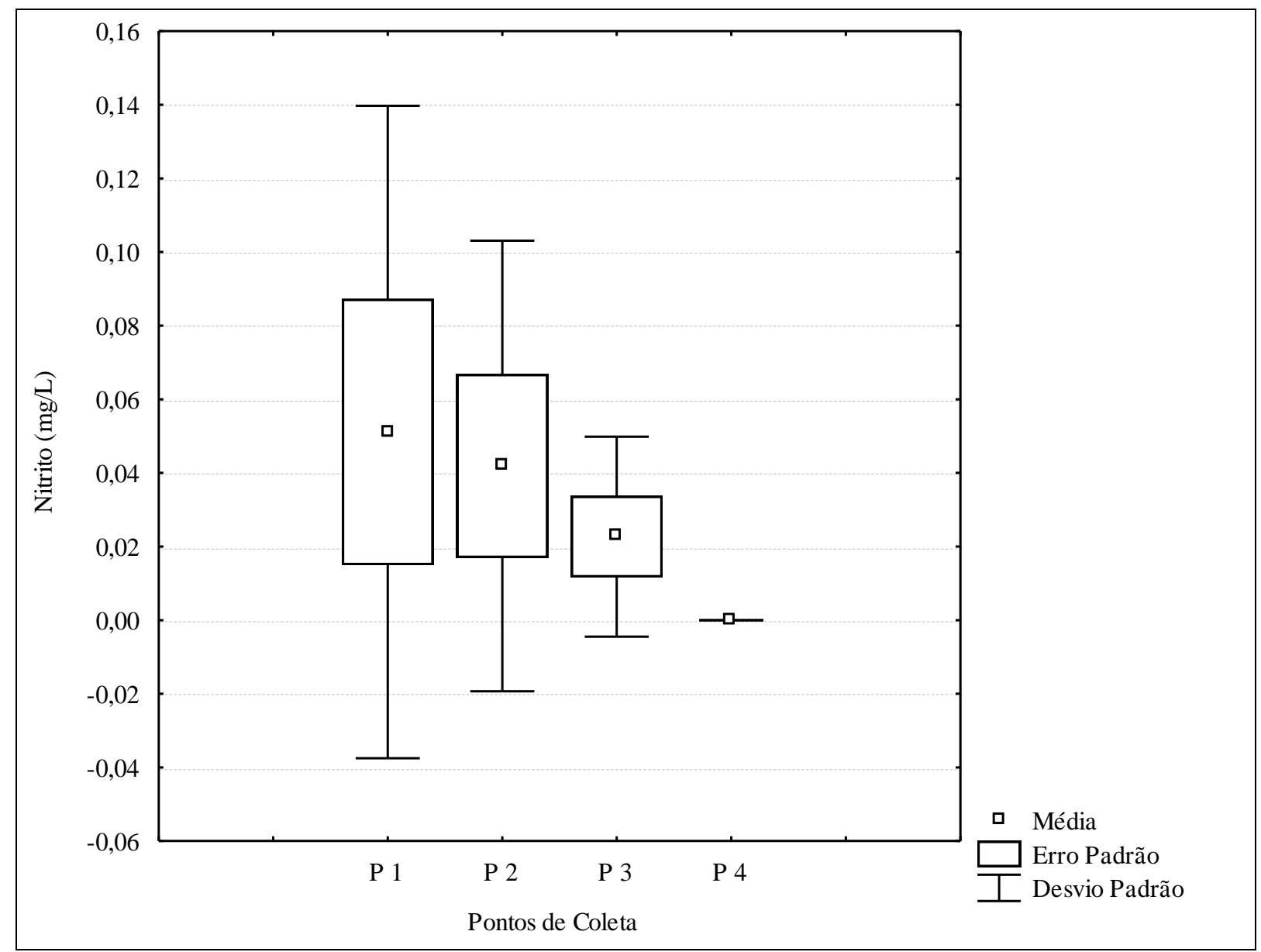

Figura 13. Média, erro padrão e desvio padrão de nitrito, para os diferentes pontos de coleta.

A Figura 14 apresenta os valores das concentrações médias de nitrato nos pontos amostrados podendo-se observar o maior valor do ponto P1 e o decréscimo nos pontos P2, P3 e ligeiro acréscimo no ponto P4. 
SANTOS, G. P.; REGO, N. A. C.; SANTOS, J. W. B.; DELANO JÚNIOR, F.; SILVA JÚNIOR, M. F. Avaliação espaço-temporal dos parâmetros de qualidade da água do rio Santa Rita (BA) em função do lançamento de manipueira. Ambi-Agua, Taubaté, v. 7, n. 3, p. 261-278, 2012. (http://dx.doi.org/10.4136/ambiagua.880)

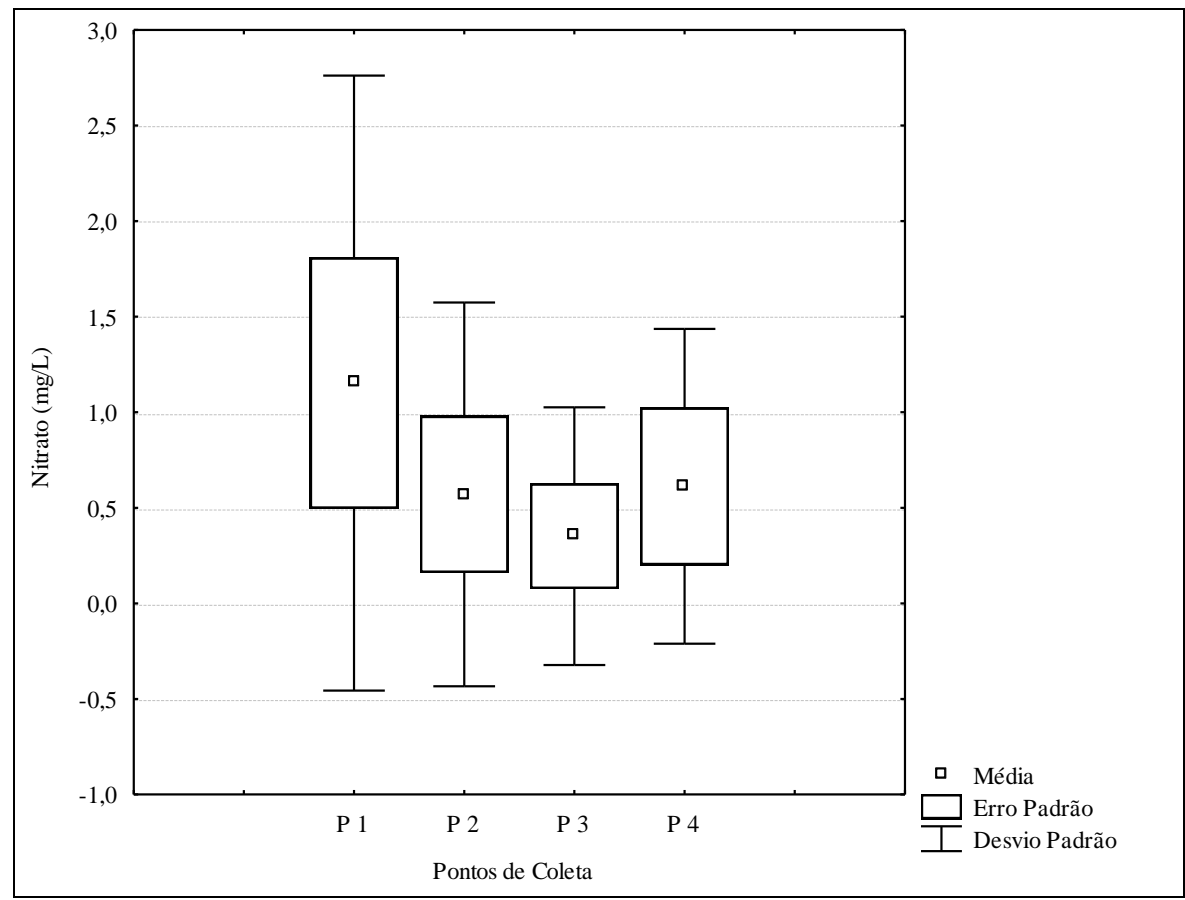

Figura 14. Média, erro padrão e desvio padrão de nitrato, para os diferentes pontos de coleta.

As menores concentrações encontradas nos pontos P2, P3 e P4 indicam que as descargas de efluentes concentram-se a montante do ponto P2 (Dias e Álvarez, 1996).

O nitrato é o composto que representa a forma mais oxidada dos compostos nitrogenados, podendo ser considerado o micronutriente responsável pelo controle de produção primária nas camadas superficiais eufóticas (Silva, 2004).

De acordo com a Resolução CONAMA 357/2005, todos os pontos analisados apresentam concentrações médias inferiores a $10 \mathrm{mg} . \mathrm{L}^{-1}$ e portanto enquadram-se como de classe I

\section{CONCLUSÕES}

Os resultados obtidos no presente trabalho mostram que os pontos de coleta de amostras de água do rio Santa Rita localizados próximos a área mais urbanizada da bacia hidrográfica apresentaram as piores condições relativas aos parâmetros avaliados.

O lançamento de manipueira que ocorre nos núcleos de Campinhos e Simão é provavelmente a causa do impacto negativo nas concentrações médias obtidas para o oxigênio dissolvido, condutividade elétrica, salinidade, amônia, nitrato, nitrito. Tais resultados indicam um forte aporte de efluentes orgânicos na cabeceira do rio, salientando-se que a água apresentou-se salobra nos três primeiros pontos de coleta.

A origem da elevada concentração de zinco no ponto de coleta $\mathrm{P} 1$ possivelmente está associado a queima de madeira, bem como lançamento de efluentes domésticos e incineração de resíduos.

As atividades agropastoris são provavelmente o causador das elevadas concentrações obtidas para o fósforo total, ferro e cobre, demonstrando desta forma, que a Bacia Hidrográfica estudada além de problemas de poluição ambiental decorrentes do beneficiamento da mandioca, apresenta um segundo aspecto de degradação dos recursos hídricos. 


\section{REFERENCIAS}

ANTONELI, V.; THOMAZ, E. L. Caracterização do meio físico da bacia do arroio Boa Vista, Guamiranga-PR. Revista Caminhos da Geografia, v. 8, n. 21, p. 46-58, 2007.

AMERICAN PUBLIC HEALTH ASSOCIATION; AMERICAN WATER WORKS ASSOCIATION; WATER ENVIRONMENT FEDERATION - APHA; AWWA; WEF. Standard methods for the examination of water and wastewater. 19th edition. Wasghington D.C., 1995.

BAHIA. Governo do Estado. Secretaria de Infraestrutura - SEINFRA. Superintendência de Recursos Hídricos - SRH. Diagnóstico das bacias hidrográficas dos rios Cachoeira e Almada: caracterização hidrológica. Vol. I. Tomo IV. Salvador, 2000.

BAHIA. Superintendência de Recursos Hídricos - SRH. Plano diretor de recursos hídricos: bacia do Recôncavo Sul. Salvador, 2004.

BARANA, A. C. Despoluição da manipueira e uso em fertilização do solo. In: SIMPÓSIO NACIONAL SOBRE A MANIPUEIRA, 1., 2008, Vitória da Conquista. Vitória da Conquista-Bahia. Anais... Vitória da Conquista: EMPBRAPA, 2008.

BRASIL. Ministério do Meio Ambiente. Resolução No 357, de 17 de março de 2005. Dispõe sobre a classificação dos corpos de água e diretrizes ambientais para o seu enquadramento, bem como estabelece as condições e padrões de lançamento de efluentes, e dá outras providências. Diário oficial [da] República Federativa do Brasil, Poder Executivo, Brasília, DF, 18 mar. 2005. Seção 1, p. 58-63.

BRANCO, S. M. Hidrologia aplicada à engenharia sanitária. 3. ed. São Paulo: CETESB/ACATESB, 1986.

CEREDA, M. P.; BRASIL, O. G.; FIORETTO, A. M. C. Microorganismos com respiração resistente ao cianeto isolados de líquido residual de fecularia. Phyton, v. 41, n. 12, p. 197-201, 1981.

CHRISTOFOLETTI, A. Análise morfométrica das bacias hidrográficas. Notícias Geomorfológicas, v. 9, n. 18, p. 19-34, 1969.

COMPANHIA DE TECNOLOGIA DE SANEAMENTO AMBIENTAL - CETESB. Qualidade das águas interiores no estado de São Paulo: índices de qualidade das águas. São Paulo, 2007.

DIAS, L. E.; ÁLVAREZ, V. H. V. Fertilidade do solo. Viçosa-MG: UFV,1996.

FERNANDES, E. S. Análise da qualidade da água do rio das Contas no município de Jequié, Bahia. 2011. Dissertação (Mestrado em Desenvolvimento Regional e Meio Ambiente) - Universidade Estadual de Santa Cruz, Ilhéus, 2011.

FIORETTO, A. M. C. Viabilidade de cultivo de Trichosporon spp. em manipueira. 1987. Dissertação (Mestrado em Agronomia) - Faculdade de Ciências Agronômicas, Universidade Estadual Júlio de Mesquita Filho, Botucatu, 1987. 
SANTOS, G. P.; REGO, N. A. C.; SANTOS, J. W. B.; DELANO JÚNIOR, F.; SILVA JÚNIOR, M. F. Avaliação espaço-temporal dos parâmetros de qualidade da água do rio Santa Rita (BA) em função do lançamento de manipueira. Ambi-Agua, Taubaté, v. 7, n. 3, p. 261-278, 2012. (http://dx.doi.org/10.4136/ambiagua.880)

HELBIG, E.; BUCHWEITZ, M. R. D. I.; GIGANTE, D. P. Análise dos teores de ácidos cianídrico e fítico em suplemento alimentar: multimistura. Revista de Nutrição, Campinas, v. 21, n. 3, p. 323-328, 2008. http://dx.doi.org/10.1590/S141552732008000300007

HESS, M. L. Tratamentos de despejos de fecularia de mandioca por oxidação biológica. Revista D.A.E., São Paulo, v. 23, n. 46. p. 29-35, 1962.

LAGE, V. F. Avaliação ambiental da qualidade da água da bacia do rio Piabanha e sua contribuição ao rio Cachoeira - Sul da Bahia. 2011. Dissertação (Mestrado em Desenvolvimento Regional e Meio Ambiente) - Universidade Estadual de Santa Cruz, Ilhéus, 2011.

LIMA, I. V.; PEDROZO, M. F. Ecotoxicologia do ferro e seus compostos. Salvador: CRA, 2001. (Cadernos de Referência Ambiental, 4).

PÉRICO, E.; CEMIN, G.; AREND, U.; REMPEL, C.; ECKHARD, R. R. Análise fisiográfica da bacia hidrográfica do Rio Forqueta, RS. In: SIMPÓSIO BRASILEIRO DE SENSORIAMENTO REMOTO - SBSR, 15., 2011, Curitiba. Anais... São José dos Campos: INPE, 2011.

PHILIPPI, A. J. R.; ROMERO, M. A.; BRUNA, G. C. Curso de gestão ambiental. Barueri: Manole, 2004.

RAMIREZ, A. V. Toxicidad del cianuro: Investigación bibliográfica de sus efectos en animales y en el hombre. Anais Faculdade de Medicina, v.71, n.1, p. 54-61, 2010.

REGO, N. A. C.; SANTOS, J. W. B.; TEIXEIRA, A. Estudos quali-quantitativos da condutividade elétrica das águas superficiais da bacia hidrográfica do Rio Cachoeira sul da Bahia. In: INSTITUTO DE GESTÃO DAS ÁGUAS E CLIMA. Gestão de recursos hídricos. Salvador, 2009. (Águas da Bahia, 3).

ROCHA, I. S.; BARROS, G. Condomínio Greenville e loteamento Vila América: um retrato da segregação sócio-espacial em Vitória da Conquista. In: COLOQUIO INTERNACIONAL DE GEOCRÍTICA, 11., 2010, Buenos Aires. La planificación territorial y el urbanismo desde el diálogo y la participación. Actas... Buenos Aires: Universidad de Buenos Aires, 2010.

SANT'ANA, A. F.; DOMENE, S. M. A. Teores de glicosídeos cianogênicos em derivados de mandioca determinados por protocolo adaptado ao laboratório de microntrientes. In: ENCONTRO DE INICIAÇÃO CIENTÍFICA, 13., 2008, Campinas. Anais... Campinas: IC-PUC, 2008.

SANTOS, A. Possibilidades e perspectivas para a sustentabilidade do cultivo da mandioca no Planalto de Conquista. 2001. Dissertação (Mestrado em Desenvolvimento Sustentável - Gestão e Políticas Ambientais) - Universidade de Brasília, Brasília, 2001.

SILVA, C. A. R. Análises físico-químicas de sistemas marginais marinhos. Rio de Janeiro: Interciências, 2004.

TONELlO, K. C.; DIAS, H. C. T.; SOUZA, A. L.; RIBEIRO, C. A. A. S.; LEITE, F. P. Morfometria da bacia hidrográfica da Cachoeira das Pombas, Guanhães-MG. Revista Árvore, v. 30, n. 5, p. 849-857, 2006. http://dx.doi.org/10.1590/S0100-67622006000500019 
SANTOS, G. P.; REGO, N. A. C.; SANTOS, J. W. B.; DElANO JÚNIOR, F.; SILVA JÚNIOR, M. F. Avaliação espaço-temporal dos parâmetros de qualidade da água do rio Santa Rita (BA) em função do lançamento de manipueira. Ambi-Agua, Taubaté, v. 7, n. 3, p. 261-278, 2012. (http://dx.doi.org/10.4136/ambiagua.880)

VILLELA, S. M.; MATTOS, A. Hidrologia aplicada. São Paulo: McGraw-Hill do Brasil, 1975. 245p. 